
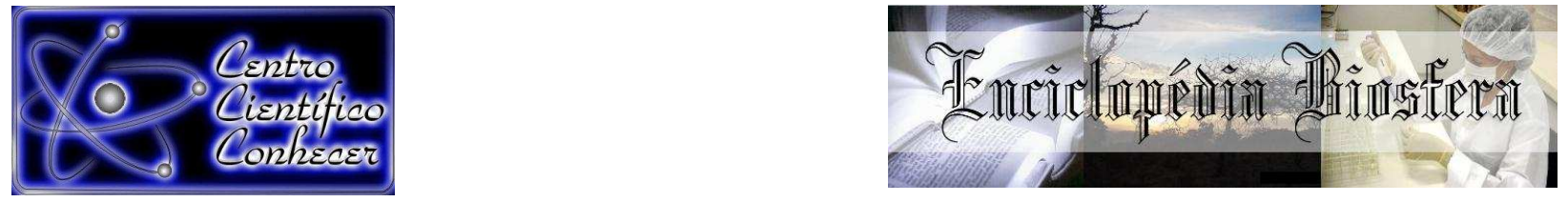

\title{
ALTERNATIVAS DE MANEJO NITROGENADO E USO DE BACTÉRIAS PROMOTORAS DE CRESCIMENTO NA CULTURA DA BATATA
}

\author{
Mariane Peripolli ${ }^{1}$, Guilherme Bergeijer da Rosa ${ }^{1}$, Alex TagliaPietra Schonell ${ }^{1}$, \\ Gerusa Massuquini Conceição ${ }^{2}$, Thomas Newton Martin ${ }^{3}$ \\ ${ }^{1}$ Graduando (a) do curso de Agronomia, Universidade Federal de Santa Maria \\ (mperipolli@gmail.com), Santa Maria, RS, Brasil. \\ 2 Doutoranda do Programa de Pós Graduação em Agronomia, Universidade Federal \\ de Santa Maria, Santa Maria, RS, Brasil. \\ ${ }^{3}$ Professor Doutor do curso de Agronomia, Universidade Federal de Santa Maria, \\ Santa Maria, RS, Brasil
}

Recebido em: 08/09/2015 - Aprovado em: 14/11/2015 - Publicado em: 01/12/2015 DOI: http://dx.doi.org/10.18677/Enciclopedia_Biosfera_2015_074

\begin{abstract}
RESUMO
Entre os fatores que podem contribuir para o aumento da produtividade da batata cabe ressaltar o uso dos fertilizantes, entre eles o nitrogênio $(\mathrm{N})$ além de outros produtos utilizados afim de promover um melhor desenvolvimento da cultura. Objetivou-se com este estudo avaliar a influência do manejo nitrogenado e utilização de manejos alternativos com o uso de bactérias promotoras de crescimento e biofertlilizantes na produção de batata. O estudo foi realizado no ano de 2014, no município de Silveira Martins-RS, onde foram realizados dois experimentos em delineamento blocos ao acaso com quatro repetições. Os tratamentos foram compostos por diferentes combinações de fertilizante nitrogenado, bactérias promotoras de crescimento, biofertlizante, Bacillus Subtilis, pseudômonas e CIATT os quais foram aplicados no sulco de semeadura e/ou no momento da amonta. Os manejos alternativos não apresentaram eficiência para número de tubérculos e produtividade total em relação ao manejo convencional utilizado na cultura da batata.
\end{abstract}

PALAVRAS-CHAVE: fertilização, produtividade, Solanum tuberosum L.

\section{NITROGEN ALTERNATIVE MANAGEMENT AND USE OF GROWTH PROMOTING BACTERIA IN THE POTATO CROP}

\begin{abstract}
Factors that may contribute to increase the potato productivity emphasizes the use of fertilizers, including nitrogen $(\mathrm{N})$ and other products used to promote better culture development. The objective of this study was to evaluate the influence of nitrogen management and use of alternative managements with the use of growth promoting bacteria and biofertlilizers in the potato production. The study was carried out in 2014 in the city of Silveira Martins, RS, where two experiments were carried out in a randomized block design with four replications. The treatments were different
\end{abstract}


combinations of nitrogen fertilizer, which growth promoting bacteria, biofertilizer, Bacillus subtilis, pseudomonas and CIATT which were applied in the planting furrow and or at the time of piles. Alternative managements not showed efficiency to number of tubers and total yield compared to conventional management used in the potato crop.

KEYWORDS: fertilization, productivity, Solanum tuberosum L.

\section{INTRODUÇÃO}

A batata (Solanum tuberosum L.) é o terceiro principal alimento no mundo, sendo superada apenas pelo arroz e trigo (FAOSTAT, 2013). Cultivada em mais de 125 países, a produção mundial é da ordem de 332,3 milhões de toneladas, com área plantada de 18,2 milhões de hectares e produtividade média de $18,3 \mathrm{t} \mathrm{ha}^{-1}$ (SILVA et al., 2014). Atualmente, seu cultivo vem ganhando espaço nos países em desenvolvimento que, na última década, liderados por China e Îndia, produziram mais da metade do total mundial (GNOCATO et al., 2014). No Brasil, é a hortaliça de maior importância econômica, em 2013 a área plantada foi de cerca de 128 mil hectares (KAWAKAMI, 2015), e em 2015, as perspectivas levam a um avanço em relação a temporada de 2014 (CARDOSO et al., 2015). Além disso, no País, a batata processada na forma de chips e palitos pré-fritos apresentou o segundo maior crescimento no setor industrial de alimentos no ano de 2010 (SILVEIRA et al., 2011).

Do ponto de vista da segurança alimentar, a batata é uma cultura de grande importância nutricional uma vez que os tubérculos são uma excelente fonte de energia oriunda dos carboidratos, ricos em sais minerais e vitaminas e apresentam proteínas de alto valor biológico (FERNANDES et al., 2015). Sabe-se que $100 \mathrm{~g}$ deste produto suprem cerca de $10 \%$ das necessidades de um adulto em tiamina, niacinas, vitamina B6 e ácido fólico; $50 \%$ de vitamina C e 10\% da demanda de proteínas, além de $840 \mathrm{mg}$ de potássio, destacando-a como uma das hortaliças mais ricas neste nutriente (PÁDUA et al., 2009).

Por ser uma cultura de ciclo curto e apresentar alta capacidade produtiva, a batateira é altamente responsiva à aplicação de nutrientes (FERNANDES \& SORATTO, 2012; LUZ et al., 2013). Dessa forma, entre os fatores que podem contribuir para o aumento da produtividade, cabe ressaltar o uso do nitrogênio $(\mathrm{N})$, o qual possui uma relação direta com a fotossíntese e crescimento vegetativo da planta (TAIRO \& NDAKIDEMI, 2013). De acordo com FERNANDES et al. (2011), a cultura é altamente responsiva a aplicação de $\mathrm{N}$, sendo que este é o segundo nutriente mais absorvido pela batateira, dessa forma um dos mais limitantes na produtividade. No Brasil, é possível encontrar recomendações de fertilização variando de 60 a $250 \mathrm{~kg} \mathrm{ha}^{-1}$ de $\mathrm{N}$, sendo que a dose ótima a ser fornecida depende de vários fatores, como produtividade esperada, pluviosidade, cultura anterior, práticas culturais, entre outros (FONTES, 2001). Além disso, a dose a ser aplicada deve otimizar o rendimento da cultura e a qualidade final do produto, maximizar a rentabilidade e reduzir os riscos de contaminação ambiental (COELHO et al., 2010). Trabalhos de pesquisa conduzidos na Embrapa Clima Temperado mostraram não haver efeito na produtividade de tubérculos ao se usar sulfato de amônio, ureia ou sulfonitrato de amônio, como fontes deste nutriente. Entretanto, MILAGRES et al. (2013), recomendam o uso do parcelamento da adubação nitrogenada na cultura da batata, visando melhorar a eficiência de utilização, pois ele proporciona algumas 
vantagens como: menor perda por lixiviação, menor perda por volatilização e redução do efeito salino.

A salinidade constitui um dos problemas mais graves para a agricultura, pois afeta consideravelmente a produtividade das culturas. Os efeitos negativos da salinidade do solo sobre as plantas são, sobretudo devidos ao potencial osmótico da solução do solo, pois a presença de elevadas concentrações de sais reduz a disponibilidade de água e, consequentemente ocorre um estresse salino, em que as plantas respondem com menores produções. (LOVELLI et al., 2000). Em Solanum tuberosum L. possibilita a redução da produção de tubérculos com calibres que não são comercializáveis, além de problemas fisiológicos como aumento da percentagem de matéria seca no caule e tubérculos, embonecamento e coração oco (LUZ et al. 2014) tornando-se economicamente inviável. Diante disso, buscam-se alternativas para reduzir os riscos ambientais causados pela utilização inadequada e às vezes excessiva de insumos pois a alta quantidade de fertilizante aplicada, cria certos problemas de ordem biológica, econômica e ambiental (SHRESTHA et al., 2010; FONTES et al., 2011).

Neste sentido, a utilização de manejos alternativos além do uso da fertilização nitrogenada pode ser uma forma de aumentar a produção agrícola, tornar o produto mais competitivo e diferenciado e, ainda, diminuir os custos para o produtor. Dentre estes vale ressaltar a utilização de bactérias que colonizam a rizosfera ou raízes e exercem efeito benéfico sobre as plantas, as chamadas rizobactérias promotoras de crescimento de plantas (RPCPs) as quais são capazes de estimular o crescimento vegetal através do aumento na disponibilidade de nutrientes na rizosfera e melhorias na estrutura do solo, produção de reguladores de crescimento, controle ou inibição da atividade de fitopatógenos, biorremediação de elementos contaminantes do solo como metais pesados e agroquímicos (AHEMAD \& MALIK, 2011; BULGARELLI et al., 2013), entre outros mecanismos. Têm sido identificadas em diversos gêneros incluindo Acinetobacter, Azospirillium, Azotobacter, Bacillus, Beijerinckia, Burkholderia, Enterobacter, Pantoea, Pseudomonas e Ralstonia (KARAKURT \& KOTAN, 2011).

Estudos evidenciam que bactéria Azospirillum brasilense, além de realizar a fixação biológica do $\mathrm{N}$ em gramíneas como o milho, na cultura da batata poderia atuar como um promotor de crescimento pela possível produção de fitormônios como o ácido indol acético, ácido indol butírico, giberelinas, citocininas e octadecanóides (KANG et al., 2009; PÉREZ-GARCÍA et al., 2011), destacando-se, sobretudo, a produção de auxina, que interfere no crescimento das plantas e pode alterar a morfologia das raízes, possibilitando a exploração de maior volume de solo. Em canola houve aumento do número de grãos por síliqua e da massa de mil grãos pela microbiolização de sementes com Azospirillum brasilense (NOSHEEN et al., 2011). Ainda os gêneros Pseudomonas e Bacillus têm sido amplamente estudados e seus benefícios observados em várias culturas. Em plantas de cebola cultivadas em campo, originadas de sementes microbiolizadas com espécies correspondentes a estes gêneros, foram obtidos acréscimos de 15,7 a 24,4\% na produção total de bulbos por hectare e de 4,3 a $13,5 \%$ na massa média de cada bulbo (HARTHMANN et al., 2010).

Diante do exposto, objetivou-se com esse estudo avaliar a influência do manejo nitrogenado e da utilização de manejos alternativos com o uso de bactérias promotoras de crescimento e biofertlilizantes na produção de batata. 


\section{MATERIAL E MÉTODOS}

O estudo foi realizado no município de Silveira Martins-RS, Brasil situada na latitude $29^{\circ} 38^{\prime} 33^{\prime \prime} \mathrm{S}$, longitude $53^{\circ}$ 35' $08^{\prime \prime} \mathrm{W}$ e $431 \mathrm{~m}$ de altitude. Segundo a classificação de Köppen, o clima da região é do tipo Cfa Subtropical úmido com verões quentes, sem estação seca definida (HELDWEIN et al., 2009). O plantio ocorreu no dia 10 de novembro de 2014 em sulcos de 5 a $10 \mathrm{~cm}$ de profundidade. Cada parcela experimental foi composta por um camaleão de dois metros de comprimento por $0,9 \mathrm{~m}$ (área experimental de $1,8 \mathrm{~m}^{2}$ ). Utilizaram-se duas fileiras laterais como bordadura.

Foram realizados dois experimentos em delineamento em blocos ao acaso com quatro repetições. Os tratamentos estão descritos na Tabela 1. Os produtos utilizados foram: inoculante biofertilizante promotor de crescimento a base de bactérias do gênero Azospirillum com garantias de $2 \times 10^{8} \mathrm{UFC} \mathrm{mL}{ }^{-1}$; complexo de nutrientes composto por fósforo $\left(\mathrm{P}_{2} \mathrm{O}_{5}\right): 22 \mathrm{~g} \mathrm{~L}^{-1}$, cobre $(\mathrm{Cu})$ : $0,55 \mathrm{~g} \mathrm{~L}^{-1}$, nitrogênio $(\mathrm{N}): 11 \mathrm{~g} \mathrm{~L} \mathrm{~L}^{-1}$, Enxofre (S): $0,22 \mathrm{~g} \mathrm{~L}^{-1}$, complexados por moléculas de oligossacarídeos e polissacarídeos; enraizador formulado a partir de extratos metabólicos de microrganismos, complexo de polissacarídeos e oligossacarídeos; produto a base de bactérias do gênero pseudômonas,produto a base de bactérias da espécie Bacillus Subtilis, produto CIATT e ureia comercial $\left(\left(\mathrm{NH}_{2}\right)_{2} \mathrm{CO}\right)$ contendo $46 \%$ de $\mathrm{N}$ a qual foi aplicada no momento da amontoa de semeadura em três doses sendo 0, 50 e $100 \%$ da recomendada para a cultura, as quais foram 0,80 e $160 \mathrm{~kg}$ $\mathrm{ha}^{-1}$. No experimento 1 os demais produtos foram aplicados no sulco de semeadura. Já no experimento 2 foram aplicados no sulco de semeadura e ou no momento da amontoa (Tabela 1).

TABELA 1. Descrição dos tratamentos aplicados em tubérculos de batata semente e no sulco de semeadura para os experimentos 1 e 2 .

Tratamentos Aplicação no sulco de semeadura Aplicação na amontoa EXPERIMENTO 1

\begin{tabular}{|c|c|c|}
\hline 1 & Testemunha & Testemunha \\
\hline 2 & - & $160 \mathrm{~kg} \mathrm{ha}^{-1} \mathrm{de} \mathrm{N}$ \\
\hline 3 & - & $80 \mathrm{~kg} \mathrm{ha}^{-1}$ de N \\
\hline 4 & $\begin{array}{c}\text { Azospirillum (A) }\left(1 \mathrm{~L} \mathrm{ha}^{-1}\right)+\text { complexo } \\
\text { de nutrientes (CP) }\left(0,5 \mathrm{~L} \mathrm{ha}^{-1}\right)\end{array}$ & $80 \mathrm{~kg} \mathrm{ha}^{-1}$ de $\mathrm{N}$ \\
\hline 5 & $A\left(1,5 L h a^{-1}\right)+C P\left(0,5 L h a^{-1}\right)$ & $80 \mathrm{~kg} \mathrm{ha}^{-1}$ de N \\
\hline 6 & $\mathrm{~A}\left(1 \mathrm{~L} \mathrm{ha}^{-1}\right)+$ Enraizador $(\mathrm{E})\left(0,5 \mathrm{~L} \mathrm{ha}^{-}\right.$ & $80 \mathrm{~kg} \mathrm{ha}^{-1}$ de N \\
\hline 7 & $A\left(1 \mathrm{Lha}^{-1}\right)+E\left(1 \mathrm{Lha}^{-1}\right)$ & $80 \mathrm{~kg} \mathrm{ha}^{-1}$ de N \\
\hline 8 & $\begin{array}{l}\mathrm{A}\left(1 \mathrm{~L} \mathrm{ha}{ }^{-1}\right)+\mathrm{CP}\left(0,5 \mathrm{~L} \mathrm{ha}{ }^{-1}\right)+ \\
\text { Pesudomonas }(\mathrm{P})\left(1 \mathrm{~L} \mathrm{ha}^{-1}\right)\end{array}$ & $80 \mathrm{~kg} \mathrm{ha}^{-1}$ de N \\
\hline 9 & $\begin{array}{c}\text { A }\left(1 \mathrm{~L} \mathrm{ha}^{-1}\right)+\mathrm{CP}\left(0,5 \mathrm{~L} \mathrm{ha}^{-1}\right)+\text { Bacillus } \\
\text { Subtilis (BS) }\left(1 \mathrm{~L} \mathrm{ha}^{-1}\right)\end{array}$ & $80 \mathrm{~kg} \mathrm{ha}^{-1}$ de $\mathrm{N}$ \\
\hline 10 & $\begin{array}{c}\mathrm{A}\left(1 \mathrm{~L} \mathrm{ha}^{-1}\right)+\mathrm{CP}\left(0,5 \mathrm{~L} \mathrm{ha}^{-1}\right)+\mathrm{CIATT} \\
\left(1 \mathrm{~L} \mathrm{ha}^{-1}\right)\end{array}$ & $80 \mathrm{~kg} \mathrm{ha}^{-1} \mathrm{de} \mathrm{N}$ \\
\hline 11 & $\begin{array}{c}A\left(1 L h a^{-1}\right)+C P\left(0,5 L h a^{-1}\right)+P(0,5 L \\
\left.h a^{-1}\right)+B S\left(0,5 L h a^{-1}\right)\end{array}$ & $80 \mathrm{~kg} \mathrm{ha}^{-1}$ de N \\
\hline 12 & $\begin{array}{c}A\left(1 L h^{-1}\right)+C P\left(0,5 L h a^{-1}\right)+P(0,5 L \\
\left.h a^{-1}\right)+B S\left(0,5 L h^{-1}\right)+\operatorname{CIATT}(0,5 L \\
\left.h a^{-1}\right)\end{array}$ & $80 \mathrm{~kg} \mathrm{ha}^{-1}$ de N \\
\hline
\end{tabular}




\begin{tabular}{|c|c|c|}
\hline & $\begin{array}{c}\left.\text { A(1L ha }{ }^{-1}\right)+ \text { CP }\left(0,5 L h a^{-1}\right)+P(0,5 L \\
\left.h a^{-1}\right)+ \text { BS }\left(0,5 L h^{-1}\right)+\text { CIATT }(0,5 L \\
\left.h a^{-1}\right)\end{array}$ & $160 \mathrm{~kg} \mathrm{ha}^{-1}$ de $\mathrm{N}$ \\
\hline \multicolumn{3}{|c|}{ EXPERIMENTO 2} \\
\hline 1 & Testemunha & Testemunha \\
\hline 2 & - & $160 \mathrm{~kg} \mathrm{ha}^{-1}$ de $\mathrm{N}$ \\
\hline 3 & - & $\mathrm{A}\left(1 \mathrm{~L} \mathrm{ha} \mathrm{h}^{-1}\right)+\mathrm{CP}\left(0,5 \mathrm{~L} \mathrm{ha} \mathrm{s}^{-1}\right)$ \\
\hline 4 & - & $A\left(1 \mathrm{Lha}^{-1}\right)+E\left(1 \mathrm{~L} \mathrm{ha} \mathrm{C}^{-1}\right)$ \\
\hline 5 & - & $\begin{array}{l}\text { A }\left(1 \mathrm{~L} \mathrm{ha} \mathrm{ha}^{-1}\right)+\mathrm{CP}\left(0,5 \mathrm{~L} \mathrm{ha} \mathrm{h}^{-1}\right)+ \\
P\left(0,5 \mathrm{~L} \mathrm{ha} \mathrm{ha}^{-1}\right)+\mathrm{BS}\left(0,5 \mathrm{ha}^{-1}\right)\end{array}$ \\
\hline 6 & $\begin{array}{c}A\left(1 L h a^{-1}\right)+C P\left(0,5 L h a^{-1}\right)+P(0,5 L \\
\left.h a^{-1}\right)+B S\left(0,5 L h a^{-1}\right)\end{array}$ & Idem sulco \\
\hline 7 & $\begin{array}{c}A\left(1 \mathrm{~L} h \mathrm{~h}^{-1}\right)+\text { CP }\left(0,5 \mathrm{~L} \mathrm{ha}^{-1}\right)+\mathrm{P}(0,5 \mathrm{~L} \\
\left.h \mathrm{a}^{-1}\right)+\mathrm{BS}\left(0,5 \mathrm{~L} \mathrm{ha}^{-1}\right)+\text { CIATT }(0,5 \mathrm{~L} \\
\left.\mathrm{ha}^{-1}\right)\end{array}$ & Idem sulco \\
\hline
\end{tabular}

O manejo e a quantidade de $\mathrm{N}$ foram realizados conforme as orientações técnicas agronômicas recomendadas da cultura (FONTES, 2005). O controle fitossanitário foi feito por meio de aplicações preventivas e de controle com defensivos químicos, sempre que necessário. A colheita foi realizada manualmente no dia 24 de fevereiro de 2015. As variáveis analisadas foram o número de tubérculos por parcela, peso médio por tubérculo e produtividade total de tubérculos. As análises estatísticas foram realizadas utilizando-se o software Genes ${ }^{\circledR}$ (CRUZ, 2006), realizando-se a análise de variância $(p>=0,05)$ e quando significativo aplicouse o teste de comparação de médias Scott-Knott.

\section{RESULTADOS E DISCUSSÃO}

Nas Tabelas 2 e 3 estão apresentados os resultados da comparação de médias referentes as variáveis: número de tubérculos (NT), massa média de tubérculos (PMT) e produtividade total (PT). A produtividade total de tubérculos variou entre 3,22 a $15,38 \mathrm{tha}^{-1}$ (Tabela 2), entretanto o potencial produtivo da cultura é de 30 a 40 observando-se, portanto que a produtividade foi abaixo da esperada, devido, principalmente a ocorrência de altos índices pluviométricos e temperaturas elevadas, aumentando a incidência de doenças e consequentemente reduzindo a produção. Ainda, no período de colheita, as chuvas continuaram intensas atrasando a retirada dos tubérculos do campo e provocando perdas por apodrecimento.

TABELA 2. Número de tubérculos (NT), massa média de tubérculos (g) (PMT) e produtividade total $\left(t \mathrm{tha}^{-1}\right)$ (PT) em tubérculos de batata submetidos a 12 tratamentos para o experimento 1 .

\begin{tabular}{cccc}
\hline Tratamentos & NT & PMT & PT \\
\hline 1 & $39,00 \mathrm{a}^{*}$ & $66,08 \mathrm{~g}$ & $15,38 \mathrm{a}$ \\
\hline 2 & $29,00 \mathrm{c}$ & $77,61 \mathrm{e}$ & $9,45 \mathrm{c}$ \\
\hline 3 & $19,00 \mathrm{f}$ & $69,74 \mathrm{f}$ & $9,18 \mathrm{c}$ \\
\hline 4 & $17,25 \mathrm{~g}$ & $86,27 \mathrm{c}$ & $8,00 \mathrm{~d}$ \\
\hline 5 & $16,75 \mathrm{~g}$ & $80,69 \mathrm{c}$ & $8,59 \mathrm{~d}$ \\
\hline 6 & $23,25 \mathrm{e}$ & $90,13 \mathrm{~b}$ & $10,28 \mathrm{c}$ \\
\hline 7 & $26,50 \mathrm{~d}$ & $79,54 \mathrm{~d}$ & $11,48 \mathrm{~b}$ \\
\hline 8 & $16,50 \mathrm{~g}$ & $69,85 \mathrm{f}$ & $6,39 \mathrm{e}$ \\
\hline
\end{tabular}




\begin{tabular}{cccc}
\hline 9 & $13,75 \mathrm{i}$ & $78,71 \mathrm{e}$ & $6,21 \mathrm{e}$ \\
\hline 10 & $7,00 \mathrm{j}$ & $78,58 \mathrm{e}$ & $3,22 \mathrm{f}$ \\
\hline 11 & $33,25 \mathrm{~b}$ & $60,54 \mathrm{~h}$ & $11,17 \mathrm{~b}$ \\
\hline 12 & $15,75 \mathrm{~h}$ & $101,55 \mathrm{a}$ & $9,69 \mathrm{c}$ \\
\hline 13 & $18,00 \mathrm{f}$ & $90,93 \mathrm{~b}$ & $8,41 \mathrm{~d}$ \\
\hline
\end{tabular}

*Médias seguidas por letras diferentes na coluna diferem estatisticamente pelo Teste de Scott-Knott $(\mathrm{P}<0,05)$.

A partir dos resultados obtidos através do teste de Scott-Knott, observou-se que mesmo sendo a cultura exigente em N, no primeiro experimento (Tabela 2) o tratamento 1 (testemunha) possui as maiores médias para as variáveis: número de tubérculos e produtividade total sendo respectivamente, 39 e $15,38 \mathrm{t} \mathrm{ha}^{-1}$ quando comparado com os demais tratamentos. Isso pode ter ocorrido devido a ocorrência de mineralização durante a aplicação do nitrogênio na forma de ureia que pode, por sua vez, causar danos às plantas (CAO \& TIBBITTES, 1993) e liberação de amônia durante o processo de hidrólise elevando os níveis de amônio do meio (FERREIRA et al., 2001). CARDOSO et al. (2007) e SILVA et al. (2014a) alertam sobre a utilização de nitrogênio na cultura da batata, uma vez que, segundo estes autores o uso inadequado deste fertilizante pode estimular maior produção de folhagem, reduzir a massa seca e o amido nos tubérculos, retardar a maturação e prolongar a duração do período vegetativo, resultando em menor produtividade. Nesse sentido, FERNANDES et al. (2011), também ressaltam a importância em relação aos macronutrientes, principalmente para nitrogênio e potássio no manejo da adubação de acordo com a cultivar.

Além dos motivos mencionados acima, pode-se atribuir a falta de resposta dos tratamentos aplicados neste estudo ao fato de que os isolados introduzidos, por se tratarem de microrganismos vivos, podem ter encontrado dificuldade de se estabelecer e sobreviver em condições de campo (ATKINSON \& WATSON, 2000). Segundo (COELHO et al., 2007) embora haja inúmeros relatos positivos sobre as RPCPs quanto ao aumento na produção das culturas, crescimento de plantas e supressão de doenças, a utilização desses microrganismos nem sempre tem fornecido bons resultados em função do seu curto período de sobrevivência quando submetidos a condições do ambiente, oque pode significar um obstáculo para sua utilização comercial. Também KLOEPPER et al. (1980), relatam que a variabilidade observada em estudos de inoculação de plantas com bactérias com o objetivo de se obter incrementos no rendimento é ocasionada provavelmente por falhas em introduzir a bactéria na rizosfera. Ainda, fatores como a utilização de estirpes ineficazes, viabilidade da bactéria introduzida, tipo e temperatura do solo e constituição da comunidade microbiana nativa afetam a sobrevivência das bactérias, a colonização das raízes e a persistência na rizosfera (ARDAKANI et al., 2011).

No tratamento 12, embora a produtividade não tenha apresentado as melhores médias $\left(9,69 \mathrm{t} \mathrm{ha}^{-1}\right)$, pode-se observar que onde houve a utilização de manejos alternativos e aplicação de fertilização nitrogenada a massa média de tubérculos foi de $101,55 \mathrm{~g}$, o que os classifica como tubérculos de tamanho médio, evidenciando que a combinação de Azospirillum $\left(1 \mathrm{~L} \mathrm{ha}^{-1}\right)+\mathrm{CP}\left(0,5 \mathrm{~L} \mathrm{ha}^{-1}\right)+$ Pseudomonas $\left(0,5 \mathrm{~L} \mathrm{ha}^{-1}\right)+$ Bacillus Subtilis $\left(0,5 \mathrm{~L} \mathrm{ha}^{-1}\right)+$ CIATT $\left(0,5 \mathrm{~L} \mathrm{ha}{ }^{-1}\right)$ no sulco de semeadura e $80 \mathrm{~kg} \mathrm{ha}^{-1}$ no momento da amontoa é uma alternativa na busca de maior lucratividade. Uma vez que os consumidores têm preferência por tubérculos medianos (ABBA, 2015), e sabe-se que o valor comercial do produto está intimamente relacionado com a sua qualidade visual. 
$\mathrm{Na}$ Tabela 3 tem-se os resultados referentes ao experimento 2. Através da análise de variância, não se observou diferenças significas entre os tratamentos, mesmo quando foram aplicados os diferentes manejos no sulco de semeadura e posteriormente no momento da amontoa. Semelhante ao observado no experimento 1, não foi observado um efeito promissor na utilização dos diferentes manejos sobre as variáveis analisadas na cultura da batata. Diante disso, infere-se que são necessários ajustes constantes no programa de fertilização de $\mathrm{N}$, bem como possibilitar maiores entendimentos a respeitos de novos manejos a serem utilizados na cultura da batata, uma vez que no sistema de manejo atual de produção podem estar ocorrendo gastos desnecessários com insumos, acarretando em decréscimos de produtividade e de qualidade dos tubérculos como já foi constado em outros países por ILIN et al. (2000) e BELANGER et al. (2002).

TABELA 3. Número de tubérculos (NT), peso médio de tubérculos (PMT, g) e produtividade total (PT, $\mathrm{t} \mathrm{ha}^{-1}$ ) em tubérculos de batata submetidos a seis tratamentos para o experimento 2 .

\begin{tabular}{cccc}
\hline Tratamentos & NT & PMT & PT \\
\hline 1 & 19,25 & 76,08 & 7,89 \\
\hline 2 & 23,50 & 69,82 & 8,30 \\
\hline 3 & 35,00 & 65,49 & 10,01 \\
\hline 4 & 20,75 & 83,79 & 10,55 \\
\hline 5 & 28,50 & 57,14 & 11,31 \\
\hline 6 & 18,00 & 78,1775 & 7,67 \\
\hline
\end{tabular}

\section{CONCLUSÃO}

Os manejos alternativos com, bactérias promotoras de crescimento, complexo de nutrientes, enraizador e CIATT não apresentaram eficiência para número de tubérculos e produtividade total em relação ao manejo convencional utilizado na cultura da batata.

A utilização de manejos alternativos associados à fertilização nitrogenada proporcionou uma maior homogeneidade em relação ao tamanho, produzindo tubérculos medianos.

\section{REFERÊNCIAS}

AHEMAD, M.; MALIK, A. Bioaccumulation of heavy metals by zinc resistant bacteria isolated from agricultural soils irrigated with wastewater. Bacteriology Journal, v.2, p.12-21, 2011. ULR: http://scialert.net/abstract/?doi=bj.2012.12.21/ DOI: 10.3923/bj.2012.12.21.

ARDAKANI, M.R.; MAZAHERI, D.; MAFAKHERI, S.; MOGHADDAM, A. Absorption efficiency of $\mathrm{N}, \mathrm{P}, \mathrm{K}$ through triple inoculation of wheat (Triticum aestivum $\mathrm{L}$.) by Azospirillum brasilense, Streptomyces sp., Glomus intraradicesand manure application. Physiology and Molecular Biology of Plants, v.17, p.181-192, 2011. ULR: http://www.ncbi.nlm.nih.gov/pmc/articles/PMC3550541/ Doi: 10.1007/s12298011-0065-7 
ASSOCIAÇÃO BRASILEIRA DA BATATA (ABBA). Variedades. Disponível em: http://www.abbabatatabrasileira.com.br/variedades.asp. Acesso em: 05 de setembro de 2015.

ATKINSON, D. C.; WATSON, A. The beneficial rhizosphere: A dynamic entity. Applied Soil Ecology, v.15, p.99-104, 2000.

ULR:http://ac.els-cdn.com/S0929139300000846/1-

s2.0S0929139300000846main.pdf?_tid=f39b8936-79a0-

11e5b75b00000aab0f01\&acdnat=1445616969_df49723e0478d43e46cfe4e8c6552ac 9/DOI: 10.1016/S0929-1393(00)00084-6.

BELANGER, G.; WALSH, J. R.; RICHARDS, J. E.; MILBURN, P. H.; ZIADI, N. Nitrogen fertilization and irrigation affect tuber characteristics of two potato cultivars. American Journal of Potato Research, v.79, p.269-279,2002. ULR: http://download.springer.com/static/pdf/14/art\%253A10.1007\%252FBF02986360.pdf ?originUrl=http\%3A\%2F\%2Flink.springer.com\%2Farticle\%2F10.1007\%2FBF029863 60\&token2=exp=1445618234 acl=\%2Fstatic\%2Fpdf\%2F14\%2Fart\%25253A10.1007 \%25252FBF02986360.pdf\%3ForiginUrl\%3Dhttp\%253A\%252F\%252Flink.springer.co $\mathrm{m} \% 252 \mathrm{Farticle} \% 252 \mathrm{~F} 10.1007 \% 252 \mathrm{FBF} 02986360^{*} \sim \mathrm{hmac}=007413 \mathrm{fe} 377 \mathrm{e} 2 \mathrm{e} 49 \mathrm{cdab} 4$ 1fbfe7081879c5ce686bd163fa8d483f8515679bc95/ DOI: 10.1007/BF02986360.

BULGARELLI, D.; SCHLAEPPI, K.; SPAEPEN, S.; THEMAAT, E.V.L. Van; SCHULZE-LEFERT, P. Structure and functions of the bacterial microbiota of plants. Annual Review of Plant Biology, v.64, p.807-838, 2013. ULR: http://www.annualreviews.org/doi/pdf/10.1146/annurev-arplant-050312-120106/

DOI: 10.1146/annurev-arplant-050312-120106.

CAO, W. R.; TIBBITS, T. W. Study of various $\mathrm{NH} 4+/ \mathrm{NO} 3$ - mixtures for enhancing growth of potatoes. Journal of Plant Nutrition, v.16, p.1691-1704, 1993. ULR: http://www.tandfonline.com/doi/pdf/10.1080/01904169309364643/DOI:10.1080/0190 $\underline{4169309364643 .}$.

CARDOSO AD; ALVARENGA MAR; MELO TL; VIANA AES. Produtividade e qualidade de tubérculos de batata em função de doses e parcelamentos de nitrogênio e potássio. Ciência e Agrotecnologia,v.31, p.1729-1736, 2007. ULR: http://www.scielo.br/pdf/cagro/v31n6/a19v31n6.pdf/DOl:http://dx.doi.org/10.1590/S14 1370542007000600019.

COELHO, F. S.; FONTES, P. C. R.; PUIATTI, M.; NEVES, J. C. L.; SILVA, M. C. de. Dose de nitrogênio associada à produtividade de batata e índices do estado de nitrogênio na folha. Revista Brasileira de Ciência do Solo, v.34, p.1175-1183, 2010. ULR: http://www.scielo.br/pdf/rbcs/v34n4/17.pdf/.

COELHO, L. F.; FREITAS, S. S.; MELO, A. M. T. et al. Interação de bactérias fluorescentes do gênero Pseudomonase de Bacillus spp. com a rizosfera de diferentes plantas. Revista Brasileira de Ciência do Solo, v.31, p.1413-1420, 2007. ULR:http://www.scielo.br/scielo.php?script=sci_arttext\&pid=S0100068320070006000 18/ DOI: http://dx.doi.org/10.1590/S0100-06832007000600018. 
CRUZ, C. D. Programa Genes: estatística experimental e matrizes. Viçosa: Editora UFV, p. 382, 2006.

FAOSTAT. The agricultural production domain covers. Acessado em 02 de jun. de 2015. Online. Disponível em: http://www.fao.org/crop/statistics.html. Acesso em 20 de outubro de 2015.

FERNANDES A. M; SORATTO R. P; BEATRICE L. S. R. Extração e exportação de nutrientes em cultivares de batata: I - macronutrientes. Revista Brasileira de Ciência do Solo v.35, p.2039-2056, 2011. ULR: http://www.scielo.br/pdf/rbcs/v35n6/a20v35n6.pdf.

FERNANDES, A. M.; SORATTO, R. P. Nutrição mineral, calagem e adubação da batateira. Botucatu: FEPAF, 2012.

FERNANDES, A. M.; SORATTO, R. P.; MORENO, L. A.; EVANGELISTA, R. M. Qualidade de tubérculos frescos de cultivares de batata em função da nutrição fosfatada. Bragantia, v.74, n.1, p.102-109, 2015. ULR: http://www.scielo.br/pdf/brag/v74n1/0006-8705-brag-74-1-102.pdf/ $\quad$ DOI: http://dx.doi.org/10.1590/1678-4499.0330.

FERREIRA, V. P.; ROCIO, A. C.; ROSSONI, G.; NICOULAUD, B. A. L. Resposta da alface à fertilização nitrogenada. Horticultura Brasileira, v.19, n.2, p. 253, 2001.

FONTES PCR; BRAUN H; BUSATO C; CECON PR. Economic optimum nitrogen fertilization rates and nitrogen fertilization rate effects on tuber characteristics of potato cultivars. Potato Research, v.53, p.167-179, 2010.

FONTES, P. C. R. Diagnóstico do estado nutricional das plantas. Viçosa, MG, Universidade Federal de Viçosa, p.122, 2001.

GNOCATO, F. S.; BISOGNINI, D. A.; KIELSEI, P.; COMIRANI, M.; SOUZA, Z. S. Variação nos ganhos de seleção para caracteres de qualidade de tubérculos de batata na região Sul do Brasil. Ciência Rural, v.44, n.1, 2014. ULR: http://www.scielo.br/scielo.php?script=sci_arttext\&pid=S0103-84782014000100009/

DOI: http://dx.doi.org/10.1590/S0103-84782013005000147.

HARTHMANN, O. E. L.; MÓGOR, A. F.; WORDELL FILHO, J. A.; LUZ, W. C. da. Rizobactérias no crescimento e na produtividade da cebola. Ciência Rural, v.40, p. 462-465, 2001. ULR: http://www.scielo.br/scielo.php?pid=S010384782010000200033\&script=sci_arttext. DOI:http://dx.doi.org/10.1590/S010384782009005000256 .

HELDWEIN, A. B.; BURIOL, G. A.; STRECK, N. A. O clima de Santa Maria. Ciência e Ambiente, v.38, p.43-58, 2009.

ILIN, Z.; DJUROVKA, M.; MARKOVIC, V.; BRANKA LAZIC. Effect of mineral nitrogen concentration in soil and irrigation on $\mathrm{NO} 3$ content in potato tubers. Acta Horticulturae, v.533, p.411-417, 2000. URL: 
KANG, S. M.; JOO, G. J.; HAMAYUN, M.; NA, C. I.; SHIN, D. H.; KIM, H. Y.; HONG, J. K.; LEE, I. J. Gibberellin production and phosphate solubilization by newly isolated strain of Acinetobacter calcoaceticus and its effect on plant growth. Biotechnology
Letters, v.31,
p.277-
281 ,

2009.URL:http://link.springer.com/article/10.1007\%2Fs10529-008-

98672/DOI:10.1007/s10529-008-9867-2.

KARAKURT, H.; KOTAN, R. Effects of plant growth promoting rhizobacteria on fruit set, pomological and chemical characteristics, color values, and vegetative growth of sour cherry (Prunus cerasus cv. kütahya). Turkish Journal of Biology, v.35, p. 283291, 2011. URL: http://dergipark.ulakbim.gov.tr/tbtkbiology/article/view/5000021456 DOI: 10.3906/biy-0908-35.

KAWAKAMI, J. Redução da adubação e doses e parcelamento de nitrogênio no crescimento e produtividade de batata. Horticultura brasileira, v.33, p.168-173, 2015. URL:http://www.scielo.br/scielo.php?pid=S010205362015000200006\&script=sci_arttext/ DOI: 10.1590/S0102053620150000200006.

KLOEPPER, J. W.; SCHROTH, M. N.; MILLER, T. D. Effecs of rhizosphere colonization by plant growth-promoting rhizobacteria on potato plant development and yield. Ecology and Epidemiology, v.70, p.1078-1082,1980. URL: https://www.apsnet.org/publications/phytopathology/backissues/Documents/1980Arti cles/Phyto70n11_1078.pdf.

LUZ, J. M. Q.; QUEIROZ, A. A.; BORGES, M.; OLIVEIRA, R. C.; LEITE, S. S.; CARDOSO, R. R. Influence of phosphate fertilization on phosphorus levels in foliage and tuber yield of the potato cv. Ágata. Semina: Ciências Agrárias, v.34, p.649-656, 2013.

URL: http://www.uel.br/revistas/uel/index.php/semagrarias/article/view/11497/DOI:10.5433/ 1679-0359.2013v34n2p649.

LUZ, J.M.Q.; QUEIROZ, A.A.; OLIVEIRA, R.C. Teor crítico foliar de nitrogênio na batata 'Asterix' em função de doses de nitrogênio. Horticultura Brasileira, v.32, p.225-229, 2014. URL: http://www.scielo.br/scielo.php?script=sci_arttext\&pid=S010205362014000200225\&lng=pt\&nrm=iso\&tlng=pt DOI: $\quad 10.1590 / S 0102-$ 05362014000200019.

MILAGRES, C. C.; FONTES, P. C. R.; PUIATTI, M.; SILVA, L. J. Mini-tubérculos de batata semente básica produzidos sob parcelamento e doses de nitrogênio em substrato. Horticultura Brasileira, v.31 n.3, $2013 . \quad$ URL: http://www.scielo.br/scielo.php?script=sci_arttext\&pid=S0102-05362013000300016 DOI: 10.1590/S0102-05362013000300016.

NARDINI, R.; Galeskas, H.; SILVEIRA, J. Hortifruti Brasil, jul. 2011. Disponivel em: $<$ http://www.cepea.esalq.usp.br/hfbrasil/edicoes/103/full.pdf>.Acesso em: 20 outubro de 2015. 
NOSHEEN, A.; BANO, A.; ULLAH, F. Nutritive value of canola (Brassica napus L.) as affected by plant growth promoting rhizobacteria. European Journal of Lipid Science and Technology, v.113, p.1342-1346, 2011. URL: http://onlinelibrary.wiley.com/doi/10.1002/ejlt.201000549/abstract/_ DOI: 10.1002/ejlt.201000549.

PÁDUA, J. G. Cultura da batata: tecnologia e perspectiva. Informe agropecuário, v. 30, p.35-43, 2009.

PÉREZ-GARCíA, A.; ROMERO, D.; VICENTE, A. Plant protection and growth stimulation by microorganisms: biotechnological applications of Bacilli in agriculture. Current Opinion in Biotechnology, v.22, p.187-193, 2011. URL: http://www.ncbi.nlm.nih.gov/pubmed/21211960/DOI: 10.1016/j.copbio.2010.12.003. SHRESTHA R. K; COOPERBAND L. R; MACGUIDWIN AE. Strategies to reduce nitrate leaching into groundwater in potato grown in sandy soils: case study from North Central USA. American. Journal of Potato Research, v.87, p.229-244, 2010. URL: $\quad$ http://link.springer.com/article/10.1007\%2Fs12230-010-9131-x DOI: 10.1007/s12230-010-9131-x.

SILVA, G. O.; BORTOLETTO, A. C.; PONIJALEKI, R.; MOGOR, A. F.; PEREIRA, A. $\mathrm{S}$. Desempenho de cultivares nacionais de batata para produtividade de tubérculos. Revista Ceres, v.61, p.752-756, 2014.URL: http://www.scielo.br/scielo.php?script=sci_arttext\&pid=S0034-737X2014000500020 DOI: 10.1590/0034-737X201461050020.

SILVA, G. O.; PEREIRA, A. S.; SUINAGA FA; PONIJALEKI R. Adubação nitrogenada no rendimento da cultivar de batata BRS Ana. Horticultura Brasileira, v.32, p.107-110, 2014a. URL: http://www.scielo.br/scielo.php?script=sci_arttext\&pid=S0102-05362014000100107 DOI: 10.1590/S0102-05362014000100018.

SILVA, M. C. C.; FONTES, P. C. R. Nutrição - Manejo integrado a adubação nitrogenada na cultura da batata. Associação Brasileira de batata. 21, 2008. Disponívelem:http://www.abbabatatabrasileira.com.br/2008/revista.asp?id REVCAT $=29 \&$ id REVCON=671. Acesso em 20 de setembro de 2015.

SILVEIRA, J. et al. Hortifruti Brasil, jul. 2011. Disponivel em: <http://www.cepea.esalq.usp.br/hfbrasil/edicoes/103/mat_capa. pdf> . Acesso em: 20 outubro de 2015.

TAIRO, E. V. ; NDAKIDEMI P. A. Micronutrients uptake in soybean (Glycine max L.) as affected by Bradyrhizobium japonicum inoculation and phosphorus (p) supplements. World, v.1, n.1, p.1-9, 2013. ULR: file://D:/Documentos\%20Nao\%20Deletar/Downloads/Micronutrients\%20P.pdf. 